\title{
3.11
}

\section{O relevante papel da Defensoria Pública na garantia do direito à saúde e na construção do SUS}

The important role of the Public Defenders in ensuring the right to health and in the construction of the health system

\section{Ramiro Nóbrega Sant'Ana}

Mestre em Direito, Estado e Constituição; Doutorando em Direito. Professor do UNICEUB. Defensor Público do Distrito Federal. Coordenador do Núcleo de Saúde da Defensoria Pública do Distrito Federal. Brasília, Brasil.

Resumo: O trabalho destaca a importância que a Judicialização desempenha na concretização das politicas publicas de saúde. Nesse contexto, a Defensoria Pública tem destacado papel na promoção de acesso aos serviços de saúde para a população mais carente, que depende exclusivamente do SUS. Ao desafio de garantir acesso individual soma-se a necessidade de cooperação entre as instituições do sistema de justiça e os gestores do SUS para a estruturação desse patrimônio nacional. O trabalho conclui que a Defensoria deve promover articulação entre as demandas individuais que the são postas e a necessidade de colaborar para o desenvolvimento do SUS.

Palavras-chave: Direito à saúde; judicialização; Defensoria Pública.

Key-words: Right to health; judicialization; public defenders.

A Sra. Maria de Lourdes entra em mais uma consulta com seu oncologista na esperança que o tratamento tenha evoluído. O doutor se mostra preocupado e diz que ela não reagiu bem. Entrega à Sra. Maria relatório médico e informa que será necessário iniciar o uso do novo medicamento descrito e realizar um exame complexo. Preocupada Dona Maria pergunta: em qual posto de saúde eu pego esse remédio, Doutor? Em qual hospital faço esse exame? O médico Ihe responde: Dona Maria, vou Ihe dar um conselho: procure a Defensoria Pública. 
Situações desconcertantes como esse caso hipotético ocorrem diariamente nas unidades do Sistema Único de Saúde (SUS) de vários estados brasileiros e no Distrito Federal. São apenas consequências do fenômeno que se tornou a Judicialização da Saúde: a intervenção e o controle judicial sobre as políticas públicas e serviços de saúde.

A judicialização das políticas públicas encontrou nos serviços de saúde um campo fértil para o seu desenvolvimento. As amplas bases constitucionais do direito à saúde somadas ao contexto da saúde brasileira colocaram nas mãos do Judiciário responsabilidade nova e desafiadora: definir a prestação de serviços de saúde. A dimensão do debate da saúde no Judiciário tem aumentado de forma exponencial e repercute em todos os Poderes da Federação nos seus três níveis ${ }^{1}$. Paralelamente a esse crescimento do papel desempenhado pelo Judiciário, também aumentam as críticas, pelos gestores, à postura assumida pelos magistrados, defensores públicos e promotores de justiça. Nesse contexto, desempenha papel cada vez mais relevante a instituição Defensoria Pública, no âmbito estadual, distrital e federal.

A compreensão da relevância da Defensoria Pública na garantia do direito à saúde, bem como na construção e aprimoramento do SUS, é foco deste artigo. Para cumprir esse objetivo iniciaremos por registros importantes sobre a construção do SUS no Brasil e o desenvolvimento dos serviços de saúde em nosso país. A partir disso, estarão postas as condições para lançar a hipótese desse artigo: a Defensoria Pública é amplificadora dos anseios da população carente por melhores serviços de saúde.

\section{A Construção do SUS e do direito à saúde no Brasil}

A saúde é direito de todos, com garantia de acesso igualitário, mediante atendimento integral, gestão descentralizada e participação social. Essa é formulação a que foi dada na Constituição de 1988, a primeira a considerar a saúde como um

\footnotetext{
${ }^{1}$ Apenas para ilustrar a dimensão tomada pela Judicialização, registra-se que o tema foi objeto de Audiência Pública no Supremo Tribunal Federal entre abril e maio de 2009. No Legislativo, se multiplicaram as tentativas de criar critérios mais claros e restritivos ao acesso à assisténcia Farmacêutica (Lei n. 12.401 e Decreto Federal 7.508/2011). No Poder Executivo, foram criadas assessorias especializadas no Ministério da Saúde e nas secretarias de saúde, além de divulgação de estratégias de defesa pelo CONASS (CONASS, 2011).
} 
direito de acesso universal e igualitário. A situação antes da Constituição de 1988 era bem diversa.

A saúde pública antes de 1988, no regime militar, era caracterizada por uma medicina social dominada por interesse de grupos privados. Nas décadas de 60 e 70, assistiu-se a uma privatização da assistência médica promovida pelo Estado, que se institucionalizou mediante a captura da despesa social por grupos privados. O Estado comprava os serviços médicos do setor privado, e, assim, os grupos privados passaram a se beneficiar de um 'mercado cativo'. A conseqüência da expansão desse modelo foi que a saúde disponibilizada aos cidadãos, ao contrário de ser universalizada, sujeitou-se a limitações econômicas, decorrentes dos preços atribuídos aos serviços, resultando em restrições diferenciadas de acesso para muitos usuários (Castro, 2003, p. 384).

Persistia, portanto, a despreocupação pela garantia da saúde do cidadão (Carvalho \& Santos, 2002, p. 36). O modelo médico-assistencial então mantido pela ditadura assentava-se na formação e manutenção de três papéis principais: o Estado, como grande financiador por intermédio da Previdência Social; o setor privado nacional assistencial-curativo, como grande prestador de serviços; e o setor internacional, como grande fornecedor de insumos, equipamentos biomédicos e medicamentos (Andrade, 2001, p. 20). Os objetivos desse arranjo eram proporcionar o lucro às empresas/prestadoras e manter o trabalhador/cliente sob controle, de forma preservar sua higidez física e, por conseqüência, a força de trabalho do país.

A inclusão proporcionada por esse controle gerava também inúmeras exclusões, dentre elas a do trabalhador sem carteira de trabalho $^{2}$ e a do desempregado, que ficavam entregues à caridade pública, geralmente realizadas pelas Santas Casas. Esses e outros excluídos não eram clientes do sistema de saúde e, em raras ocasiões, estavam submetidos à sua vigilância.

A forte atuação do movimento sanitarista (Bertoli Filho, 2001, p. 62-63), na década de 80 , ensejou o surgimento de discurso voltado à defesa do direito universal à saúde e do dever do Estado em garanti-lo. Para tanto, foi convocada uma

\footnotetext{
2 "A situação tornava-se ainda mais trágica para o operário que não tinha carteira de trabalho e que por isso não podia contribuir para a caixa de sua categoria profissional. Para esse trabalhador, restava o apelo à caridade pública. Era qualificado pela administração dos hospitais filantrópicos como indigente, triste rótulo para quem perdera a saúde e não tinha o dinheiro para pagar o tratamento" (Bertolli Filho, 2001, p. 33).
} 
Conferência Nacional de Saúde ${ }^{3}$ para subsidiar a Assembléia Nacional Constituinte (Almeida et al., 2001, p. 30). Tal evento, de importância sem precedentes no desenvolvimento da saúde no Brasil, resultou na formatação de um projeto de Reforma Sanitária, caracterizado por três aspectos principais: a ampliação da noção de saúde; a garantia da saúde como direito de cidadania e dever do Estado; e a instituição de um Sistema Único de Saúde (Almeida et al., 2001, p. 31). Assim, a citada conferência, por meio da Comissão Nacional de Reforma Sanitária, influenciou profundamente a elaboração da nova Constituição ${ }^{4}$.

As principais demandas do movimento sanitarista foram acolhidas no texto da nova Constituição, e a ordem jurídica que se inaugurava representou uma redefinição profunda da compreensão constitucional acerca da saúde e do direito à saúde que surgia. A nova base da universalidade do direito à saúde não comportava à primeira vista a exclusão de nenhum cidadão. Realmente, é possível afirmar que a Constituição de 1988 trouxe mudanças para aquela medicina social que era tão bem observada no modelo do sistema de saúde que foi formado na Era Vargas e mantido até o fim da ditadura militar.

As novas bases da saúde lançadas na Constituição de 1988 foram um momento ímpar para o desenvolvimento da saúde pública brasileira. Em vários aspectos, o nosso sistema público de saúde alcançou níveis satisfatórios ou de excelência no atendimento à sociedade. Para citar apenas alguns exemplos, o Programa de HIV/Aids ${ }^{5}$ do governo federal e as diversas iniciativas quanto a diabetes são referências mundiais. Apesar desse cenário animador, sérios problemas

\footnotetext{
3 "Em março de 1986 aconteceu, em Brasília, a VIII Conferência Nacional de Saúde (CNS), um dos eventos políticos sanitários mais importantes devido ao seu caráter democrático (presença de milhares de delegados, representando usuários, trabalhadores da saúde, partidos políticos, os diferentes níveis de governo, universidade, parlamentares, ONG etc.) e, também, ao processo social que se estabeleceu a partir das conferências municipais e estaduais, como a ampliação do debate em termos de toda a sociedade" (Almeida et al., 2001, p. 30/31).

4 "Naquele momento havia o consenso entre, os participantes, de que para o setor de saúde no Brasil não era suficiente uma mera reforma administrativa e financeira mas sim uma mudança em todo o arcabouço jurídico institucional vigente que contemplasse a 'ampliação do conceito de saúde segundo os preceitos da reforma sanitária" (Andrade, 2001, p. 26).

${ }_{5}^{5}$ Para uma análise da construção das políticas públicas de combate à aids e tratamento dos soropositivos que se deu, sobretudo, na década de 90 (Parker, 1999). A mesma questão é analisada por Miranda (2007), sob uma perspectiva de valorização dos movimentos sociais, com atenção ao Movimento Nacional de Luta contra a Aids, cujas demandas se voltavam para efetivação do direito à saúde de pessoas vivendo com HIV/aids.
} 
continuaram a circundar a saúde pública no Brasil. E a exclusão mostrou novos contornos.

O fim dos institutos de previdência, com a implantação do SUS, induziu a criação de uma saúde supletiva (ou suplementar), que não dependia de financiamento do Estado e nem estava diretamente subordinada a ele $^{6}$. Ocorreu, entretanto, que a expansão do setor privado se deu à custa da perda de qualidade do setor público, fazendo com que este passasse a ser considerado o sistema dos grupos 'de baixo', e o da atenção médico supletiva (privada) o dos grupos 'de cima' (Almeida et al., 2001, p. 38). Esta é a conhecida universalização excludente.

A formação de um sistema público de saúde destinado aos pobres acarretou sérios prejuízos no desenvolvimento do SUS, especialmente porque a classe média, forte formadora de opinião, deixa de lutar por um bom sistema público de saúde, calcada em uma falsa percepção de que não necessita de seus serviços. Nesse particular, é importante destacar os apontamentos de Lenir Santos e Guido Ivan de Carvalho:

A luta pelo direito à saúde, como um direito das pessoas pobres, valoriza a saúde apenas como um direito que deve ser satisfeito no campo da assistência social, esvaziando-se de seu conteúdo de direito social e individual a ser garantido pelo poder público a qualquer cidadão. $O$ direito à saúde assim considerado (mero assistencialismo), transforma-o em 'direito dos pobres', devendo a classe média desejálo na forma de 'mercadoria', pretendendo sempre ter ou melhorar seu plano ou seguro-saúde. O direito à saúde transformado em bem de consumo dificulta a sua concretização, pois todos aqueles que, de algum modo, devem garantir a saúde pública, entendem que estão praticando assistencialismo, dando ao pobre aquilo que não pode comprar (Carvalho \& Santos, 2002, p. 45).

A valorização dos planos privados em detrimento da qualidade dos serviços públicos de saúde e a gestão da saúde pública submetida a interesses econômicos são apenas algumas das práticas recorrentes que agravam a exclusão da população com menor poder aquisitivo. De outro lado, a transferência para o setor público de procedimentos de alto custo que o sistema privado se recusa a cobrir (Salazar et al., 2003, p. 375) (carências e ausência de cobertura), a manutenção do modelo hospitalocêntrico e o abuso do poder econômico dos planos de saúde são outros

\footnotetext{
${ }^{6}$ Atualmente o setor privado é regulado pela Agência Nacional de Saúde Suplementar (ANS). A criação de uma agência reguladora somente para este setor já demonstra a importância do sistema privado e dos planos de saúde no cenário brasileiro.
} 
problemas que expõe à exclusão também as classes mais abastadas, o que indica ser falsa a sensação de segurança que a saúde suplementar oferece.

Como era de se esperar, o estabelecimento da saúde como direito universal não acabou com a exclusão provocada pelo sistema de saúde. Mas a dinâmica se alterou substancialmente. Se antes parte da população não tinha direito à saúde e era excluída do sistema, agora ele é aberto a todos.

Esta é uma das conseqüências da universalização do direito à saúde: a exclusão deixa de se apresentar de forma clara. Não é mais no âmbito do direito que a encontramos na sua forma mais nítida, mas sim na formulação e concretização das políticas públicas: na prestação deficiente, na dificuldade de acesso aos serviços de saúde, na adoção de uma lógica econômica na formulação das políticas públicas, na autoritária relação médico-paciente etc. Em verdade, muitos brasileiros passaram a ser incluídos como excluídos.

Uma conseqüência da situação descrita está na amplitude do alcance da exclusão. Se, no plano normativo, todos são incluídos, se torna mais fácil a exclusão de qualquer indivíduo. Como a população está inteiramente submetida a esse sistema, qualquer um pode ser objeto das conseqüências que ele pode gerar. Assim, não só a pessoa hipossuficiente está submetida ao SUS (Sistema Único de Saúde), mas também aquele que detém um plano de saúde privado pode ter que recorrer ao SUS, seja por uma emergência, seja por falta de cobertura ${ }^{7}$.

Assim, em que pese o notável desenvolvimento ocasionado pela criação do SUS, a nova exclusão que temos após a Constituição de 1988 é ainda mais perigosa, pois este sistema que está aberto a todos gera apenas uma inclusão formal. Todos têm direito aos serviços de saúde, mas, na realidade, poucos obtêm o almejado acesso integral. $\mathrm{E}$ as epidemias de dengue, as maternidades desativadas, os equipamentos aguardando manutenção, as filas nos hospitais, a falta de leitos, os abusos dos planos de saúde, o desabastecimentos das farmácias públicas, todos esses acontecimentos se tornam notícias de jornal que preocupam cada vez menos àqueles que se consideram incluídos (Carvalho \& Santos, 2002, p. 45).

A previsão de um direito constitucional à saúde e de um Sistema Único de Saúde não são, portanto, garantias de boa saúde para a população e não geram

\footnotetext{
${ }^{7}$ Isso porque estamos a enfocar apenas o aspecto de assistência à saúde, pois, no que tange aos serviços de vigilância sanitária prestados pelo SUS, todos os cidadãos são indistintamente alcançados.
} 
necessariamente mais cidadania, emancipação e independência dos indivíduos. São avanços constitucionais importantes, fruto de movimentos sociais históricos, mas que podem servir de instrumentos de exclusão caso a participação social que os criou não se perpetue. Aguardar que o mercado ou o Estado resolvam os problemas da saúde não parece ser um bom caminho.

\section{A judicialização da saúde: oportunidade aos excluídos}

Conforme já registrado, a construção do direito à saúde é fruto de participação social, da junção de força de setores do governo, profissionais de saúde e sociedade civil organizada. Logo, a realização efetiva desse direito pelas ações do SUS depende da manutenção e incremento dessa participação.

Infelizmente, para os setores menos favorecidos de nossa sociedade, a mobilização organizada não é simples. Ademais, muitos dos agravos de saúde que afetam as populações mais pobres tornam difícil o reconhecimento recíproco como grupo de interesse. ${ }^{8}$

O próprio acesso aos serviços mais básicos de saúde é dificultado. Simples consultas e exames demoram meses ou até anos nos postos de saúde espalhados pelo Brasil. É comum ter de buscar na capital do estado atendimentos que deveriam ser descentralizados. Os serviços do SUS destinado às parcelas mais pobres são claramente menos qualificados do que àqueles elaborados para atender de forma horizontal a população.

Basta observar que os programas mais bem sucedidos do SUS são exatamente àqueles relacionados a agravos de saúde que afetam a população de forma horizontal, ou seja, independente de sua classe social: diabetes, HIV, hipertensão, vacinação, hemofilia.

Por outro lado, os programas destinados às "doenças da pobreza" são menos destacados (tuberculose, malária, doença de chagas e hanseníase são bons exemplos). Da mesma forma, os postos de saúde e hospitais que servem à periferia

\footnotetext{
${ }^{8}$ Jessé Souza (2009), em sua conhecida obra A Ralé Brasileira, bem descreve esse fenômeno ao apontar que há forte resistência política ao pleito dos menos favorecidos, bem como estes os interessados investem sua atenção com a satisfação de necessidades prementes de alimentação, moradia e segurança. Assim, resta restringida sua capacidade de planejar e articular por melhorias na saúde de sua comunidade.
} 
tem qualidade de atendimento inferior àqueles que servem parte da classe média nas regiões centrais ${ }^{9}$. A esse atendimento seletivo feito pelo SUS, o sociólogo Jessé Souza dá o nome de má-fé institucional da saúde pública.

E como tratar então da exclusão, esse mal que assola nosso sistema público de saúde?

$\mathrm{Na}$ ausência de opções mais claras os usuários do SUS tem buscado no acesso ao Judiciário determinados serviços de saúde quando falta o amparo estatal ou a cobertura de seus planos de saúde. Esse processo foi percebido por Boaventura de Souza Santos:

As pessoas, que têm consciência dos seus direitos, ao verem colocadas em causa as políticas sociais ou de desenvolvimento do Estado, recorrem aos tribunais para as protegerem ou exigirem a sua efectiva execução (Santos, 2007, p. 19).

A possibilidade de recorrer ao Judiciário é garantia do Estado de Direito consolidada antes do texto da Constituição de 1988, mas a sua coexistência com os novos direitos conquistados criou a inevitável demanda de uso desse instrumento para dar-Ihes efetividade, em especial aos direitos sociais, que exigem atuação estatal mais ostensiva (Santos, 2007). Esse processo deve-se, em grande parte, à forma mais rápida como os direitos sociais foram positivados no Brasil, quando o comparamos com outros países, tais como os Estados Unidos, Alemanha, França e Itália. É o que o sociólogo Boaventura de Souza Santos chama de "curto-circuito histórico" (Santos, 2007, p. 20).

Esse processo fez coexistir as aspirações consolidadas pelo novo texto constitucional com a ausência de práticas políticas de participação popular e de concretização desses direitos. Tal situação deu ensejo ao incremento da intervenção judicial nas atividades estatais, pois o Poder Judiciário passou a ser cada vez mais acionado para buscar a efetiva realização dos direitos derivados da Constituição de 1988. Nesse contexto, a demanda em Juízo pelo direito à saúde é ao mesmo tempo fenômeno recente e importante.

Há, contudo, de se considerar que apenas quem tem acesso à assistência jurídica obtém acesso ao Judiciário. Logo, àqueles cidadãos excluídos da assistência

\footnotetext{
${ }^{9}$ Nesse sentido, as considerações de Jessé Souza (2009) no capítulo "A má-fé da saúde pública no Brasil", na obra A Ralé Brasileira.
} 
jurídica, inicialmente, não tiveram acesso a essa nova porta aberta pela judicialização da saúde.

Os problemas de acesso da população mais carente ao Judiciário levou alguns pesquisadores ${ }^{10}$ do tema a apontar a judicialização da saúde como movimento que aprofundava injustiças sociais, pois beneficiava as classes mais abastadas que tinham acesso a advogados. Sob esse aspecto, a judicialização da saúde seria mais uma porta que se abria à parcela privilegiada da população em detrimento do serviço prestado aos excluídos.

Nesse contexto é que surge o relevante papel da Defensoria Pública na garantia do direito à saúde dos cidadãos hipossuficientes, exatamente aqueles mais excluídos e submetidos aos serviços de pior qualidade.

\section{A Defensoria Pública e a garantia do direito à saúde}

Como já destacado, a busca do Poder Judiciário para a efetivação de direitos sociais encontrou campo fértil na saúde. Da mesma forma, a população antes excluída encontrou na instituição Defensoria Pública a chave para obter tanto o acesso à Justiça, quanto o acesso à saúde.

Assim, nos últimos dez anos em diversos estados brasileiros as diversas Defensorias Públicas se organizaram para atender a crescente demanda por serviços de saúde negados pelo SUS. Também em âmbito federal a Defensoria Pública da União viu crescer os pleitos por saúde.

Os cidadãos assistidos passaram a ser atendidos junto aos núcleos de atendimento de demandas cíveis (caso da DPU), em núcleos especializados em direitos humanos (caso de Rondônia e Bahia) ou em núcleo especializado em saúde, tal qual ocorre no Distrito Federal, Ceará, Rio Grande do Sul, dentre outros ${ }^{11}$.

O surgimento da Defensoria Pública como ator importante no novo e crescente fenômeno da Judicialização da Saúde permitiu que a inclusão gerada pela

\footnotetext{
${ }^{10}$ Vieira e Zucchi (2007) realizaram pesquisa no Município de São Paulo em 2007. No estudo das autoras, os dados relativos ao local de residência dos pacientes proponentes de ações judiciais contra o Município citado, sugerem que a população que mais acessa o Poder Judiciário naquela localidade é a que habita as regiões mais abastadas da cidade e, portanto, possui melhores condições de renda.

${ }^{11}$ Em estados brasileiros nos quais a Defensoria Pública não foi estruturada, além da atuação de advogados, tem destaque o trabalho do Ministério Público em prol da defesa, mesmo que individual, do direito à saúde.
} 
intervenção judicial beneficiasse tanto a classe média/média alta, quanto à população de baixa renda, que tem no SUS a única esperança de atendimento em saúde.

Nesse contexto, o exemplo do Distrito Federal é interessante, pois há acentuado número de ações judiciais relativas a serviços de saúde e a quase totalidade delas são promovidas pela Defensoria Pública do Distrito Federal. Nesse sentido, vale a menção ao estudo realizado pelas pesquisadores da Universidade de Brasília e da Fundação Oswaldo Cruz, Maria Célia Delduque e Sílvia Badim, que avaliaram ações judicias que tramitaram no Tribunal de Justiça do Distrito Federal entre 2005 e 2008 (Marques \& Delduque, 2009, p. 101 e 103):

A representação dos autores desses processos, em $95,4 \%$ dos casos, foi feita pela Defensoria Pública Distrital. Este dado chama a atenção para o grande protagonismo da Defensoria Pública na propositura dessas ações neste ente federado. (...) No Distrito Federal, o acesso à justiça para a obtenção de medicamentos, é permeado pela forte atuação da Defensoria Pública, que representa um ator fundamental para que a discussão sobre a judicialização da saúde se trave no DF de forma satisfatória. Esse dado sugere que a demanda de medicamentos em face do Estado é feita pelas classes média e baixa da população do Distrito Federal.

Corrobora as conclusões acima o estudo empreendido pela pesquisadora da UFMG Janaína Penalva (2011, p. 14) que analisou os julgamentos da $2^{\mathrm{a}}$ Vara de Fazenda Pública do TJDFT entre 2005 e 2010. Ao analisar seus resultados, destacou a pesquisadora:

A evidência disponível sugere que a judicialização da saúde no DF não é um fenômeno das elites. Praticamente todos os processos (95,06\%) no Distrito Federal foram conduzidos pela Defensoria Pública, o que permite presumir a hipossuficiência dos recursos. Apenas 3,64\% tiveram condução por um escritório de advocacia privada. Outros tipos de advocacia, como advogados de ONGs, escritórios modelo e a atuação do Ministério Público Federal ocorrem apenas esporadicamente.

A atuação firme e organizada da instituição Defensoria Pública em todo o Brasil permitiu a efetiva inclusão de muitos cidadãos que viviam às margens do SUS. Proporcionou acesso real aos serviços de saúde a usuários do SUS que, apesar da formal atribuição de um direito constitucional à saúde, não conseguiam acessar serviços essenciais para resguardar sua saúde ou até sua vida.

Assim, também na saúde, a Defensoria Pública é instrumento de empoderamento do cidadão carente e precursor de anseios sociais. 


\section{O papel da Defensoria Pública na construção do SUS}

A posição de protagonismo da instituição Defensoria Pública representa oportunidades para além da garantia do direito à saúde como um direito individual subjetivo a determinada prestação estatal.

O benefício à população assistida será potencializado se, somado ao esforço pela garantia do direito à saúde individual, for objetivo também da Defensoria o desenvolvimento e estruturação dos serviços de saúde. Isso porque, o direito à saúde, antes de ser um direito individual subjetivo, é um direito realizado coletivamente por meio da maior política pública brasileira: o Sistema único de Saúde.

Os locais de atendimento da Defensoria Pública espalhadas pelo Brasil recebem, diariamente, grande influxo de usuários do SUS que demandam diversos serviços de saúde. Essa parcela da população que aflui à Defensoria que procura atendimento é, contudo, apenas uma parte, uma amostra, do real problema social subjacente.

Para cada cidadão que busca a Defensoria por uma cirurgia ortopédica, certamente outros vários aguardam em suas casas, com dificuldades de locomoção, dores e desânimo. O desafio é perceber entres os casos concretos apresentados a existência de problema coletivo que deve ser enfrentado de forma diferente.

Esse desafio que se coloca a frente da Defensoria Pública também é oportunidade, pois a atuação com foco coletivo pode beneficiar muitos usuários do SUS além daqueles que buscaram a assistência jurídica de um Defensor Público.

O caminho para essa atuação coletiva passa, certamente, pela parceria institucional com outros integrantes de nosso sistema de justiça: Judiciário e Ministério Público. E, claro, pela criação de interface desse sistema de justiça com os gestores da saúde. A colaboração - e a cobrança - entre estas instituições, em todos os níveis da Federação, pode ajudar o SUS a perceber e enfrentar muitos dos entraves e obstáculos à prestação de serviço público de qualidade.

As experiências institucionais surgem em diversos estados que buscam potencializar os benefícios da Judicialização da Saúde, bem como reduzir as distorções causadas pela intervenção judicial. 
O caminho do experimentalismo institucional ${ }^{12}$ pode apontar alternativas bemsucedidas aos problemas decorrentes da judicialização das políticas de saúde.

Nesse sentido, merece menção a ação do Conselho Nacional de Justiça que, em 6 de abril de 2010, instituiu o Fórum Nacional do Judiciário para monitoramento e resolução de demandas de assistência à Saúde - Fórum da Saúde (Resolução n. 107).

O referido fórum é coordenado por um Comitê Executivo Nacional (Portaria 91/2010) e constituído por Comitês Estaduais e pelo Comitê Distrital. A experiência nacional tem rendido frutos e já foram realizados dois encontros nacionais, bem como foi ampliada a atuação para abarcar, além da saúde pública, a saúde suplementar.

Os Fóruns Estaduais e Distrital reúnem diversas instituições voltadas à concretização do direito à saúde: secretarias de saúde, Judiciário, Defensoria Pública, Ministério Público, OAB, conselhos profissionais, entre outros.

No Distrito Federal, o Comitê Distrital Executivo de Saúde (TJDFT, 2012) se reúne há mais de 2 anos e obteve importantes avanços em serviços como radioterapia, Terapia Intensiva, exames radiológicos, contratação de servidores, etc. Além disso, é espaço público de debate aberto entre as diversas instituições ${ }^{13}$, o que possibilita apresentação de demandas e o nivelamento de informações.

Às perspectivas abertas pela interação institucional soma-se a possibilidade de ações coletivas com foco na estruturação de serviços de saúde para a coletividade dos usuários do SUS. Tais iniciativas podem tanto ser objeto de atuação individual da instituição Defensoria ou de parceria com o Ministério Público ou Associações representantes da sociedade civil organizada.

\footnotetext{
12 Perspectiva interessante e complementar à que sugerimos é a proposta de "Experimentalismo Democrático" de Roberto Mangabeira Unger. O referido autor observar o direito como ferramenta de imaginação institucional e considera que a experiência fomenta variações institucionais entre as diferentes realidades, e essa contingência conduz à necessidade de buscar soluções específicas para os nossos problemas sociais. Nessa perspectiva, um projeto de transformação do SUS, portanto, exige a construção de alternativas institucionais específicas. Sobre a questão, Unger (2004, p 44) destaca que: "Quando começamos a explorar modos de assegurar as condições práticas do gozo efetivo de direitos, descobrimos que, a cada passo, há modos alternativos plausíveis de definir essas condições, e aí, uma vez definidas, de as satisfazer. Para cada direito de escolha, individual ou coletivo, há concepções plausíveis diferentes das suas condições de realização efetiva na sociedade, tal como ela é organizada hoje. Para cada concepção dessas, existem diversas estratégias plausíveis para preencher as concepções especificadas" (grifo nosso).

13 Entre os frutos da interação institucional foi criada em fevereiro de 2013 a Câmara Distrital Permanente de Mediação em Saúde, integrada pela Defensoria Pública do Distrito Federal e pela Secretaria de Saúde do DF (Portaria Conjunta n. 01/2013).
} 
Independente dos instrumentos escolhidos, é essencial que a atuação da Defensoria Pública possa ir além da defesa individual do direito à saúde, e represente vetor de desenvolvimento do SUS e incremento de qualidade da saúde pública brasileira.

\section{Conclusão}

A Constituição Federal de 1988, ao prever o direito social à saúde e estruturar o SUS, mudou profundamente o paradigma jurídico e político da saúde pública brasileira.

Nos anos que se seguiram a promulgação da Constituição, a população brasileira, especialmente àqueles mais carentes, convivem com a perplexidade entre um sistema jurídico que assegura acesso universal e integral à saúde e um sistema de saúde que ainda não oferece acesso efetivo a serviços de saúde de qualidade. Muitos cidadãos brasileiros ainda vivem excluídos da ação estatal.

A busca de garantir, pelo Judiciário, o acesso à saúde, ganhou relevância ao tempo em que se fez necessário atuação intensa da Defensoria Pública para garantir acesso à justiça não apenas às classes mais abastadas, mas efetivamente a todo cidadão brasileiro.

Ao desafio de garantir acesso individual aos serviços de saúde soma-se a necessidade de cooperação entre as instituições do sistema de justiça e os gestores do SUS para a estruturação desse patrimônio nacional.

Nesse contexto, a Defensoria Pública assume papel relevante de articulação entre as demandas individuais que lhe são postas e a necessidade de colaborar para o desenvolvimento do SUS. A capacidade de imaginar soluções institucionais e articulá-las com outros atores sociais é passo importante para enfrentar os desafios que se apresentam.

\section{Referências}

ALMEIDA, Eurivaldo Sampaio et al. Gestão de Serviços de Saúde. São Paulo: Edusp. 2001.

ANDRADE, Luiz Odorico Monteiro de. SUS Passo a Passo: Normas, Gestão e Financiamento. São Paulo: Hucitec; 2001.

BERTOLLI FILHO, Cláudio. História da Saúde Pública no Brasil. São Paulo: Ática, 2001. 
CARVALHO, Guido Ivan de; SANTOS, Lenir. Sistema Único de Saúde: Comentários à Lei Orgânica da Saúde (Leis no 8.080/90 e nº 8.142/90). Campinas: UNICAMP, 2002.

CASTRO, Marcus Faro de. Dimensões Políticas e Sociais do Direito Sanitário Brasileiro. In: ARANHA, Márcio lório. Direito Sanitário e Saúde Pública: coletânea de textos. Vol. 1. Brasília: Editora MS, 2003.

CONSELHO NACIONAL DE SECRETÁRIOS DE SAÚDE (CONASS). Assistência Farmacêutica no SUS. (Série "Para Entender a Gestão do SUS", livro 7, capitulo 6). Brasília: CONASS, 2011.

DEFENSORIA PÚBLICA DO DISTRITO FEDERAL. PORTARIA CONJUNTA № 01, DE 26 DE FEVEREIRO DE 2013. Diário Oficial do Distrito Federal.

MARQUES, Sílvia Badim; DELDUQUE, Maria Célia. A Judicialização da política de assistência farmacêutica no Distrito Federal: diálogos entre a política e o direito. Revista Tempus Actas de Saúde Coletiva; vol 5 (n4): 97-106. 2009.

MIRANDA, Adriana Andrade. Movimentos sociais, AIDS e cidadania: o direito à saúde no Brasil a partir das lutas sociais. Brasília: Dissertação de mestrado. Universidade de Brasília, 2007.

PARKER, Richard et al. Saúde, Desenvolvimento e Política: respostas frente à AIDS no Brasil. Rio de Janeiro: ABIA; São Paulo: Editora 34, 1999.

PENALVA, Janaína et al. Judicialização do Direito à Saúde: O caso do Distrito Federal. Belo Horizonte Faculdade de Filosofia e Ciências Humanas, 2010/2011.

SALAZAR, Andréa Lazzarini et al. Assistência Privada à Saúde: Regulamentação, Posição IDEC e Reflexos no Sistema Público. In: ARANHA, Márcio lório. Direito Sanitário e Saúde Pública: coletânea de textos. Vol. 1. Brasília: Editora MS, 2003.

SANTANA, Ramiro Nóbrega. Judiciário: o novo defensor da saúde? Constituição \& Democracia; (13):18-19, 2007.

SANTOS, Boaventura de Souza. Para uma Revolução Democrática da Justiça. São Paulo: Cortez, 2007.

SOUZA, Jessé (Org). A Ralé Brasileira: quem é e como vive. Belo Horizonte: UFMG, 2009.

TRIBUNAL DE JUSTIÇA DO DISTRITO FEDERAL E TERRITÓRIOS. PORTARIA GPR 1423, DE 25 OUTUBRO DE 2012. Diário de Justiça do Distrito Federal.

UNGER, Roberto Mangabeira. O direito e o futuro da democracia. São Paulo: Boitempo; 2004.

VIERA, FS; ZUCCHI, P. Distorções causadas pelas ações judiciais à política de medicamentos no Brasil. Revista de Saúde Pública; 41(2):214-222, 2007. 